\title{
Spatial interference between attended items engenders serial visual processing
}

\author{
Yusuke Yamani • Jason S. McCarley • \\ Jeffrey R. W. Mounts • Arthur F. Kramer
}

Published online: 10 November 2012

(C) Psychonomic Society, Inc. 2012

\begin{abstract}
A pair of experiments investigated the architecture of visual processing, parallel versus serial, across high and low levels of spatial interference in a divided attention task. Subjects made speeded judgments that required them to attend to a pair of color-cued objects among gray filler items, with the spatial proximity between the attended items varied to manipulate the strength of interference between attended items. Systems factorial analysis (Townsend \& Nozawa, Journal of Mathematical Psychology 39:321-359, 1995) was used to identify processing architecture. Experiment 1, using moderately dense displays, found evidence of parallel processing whether attended objects were in low or high proximity to one another. Experiment 2, using higher-density displays, found evidence of parallel selection when attended stimuli were widely separated but serial processing when they were in high proximity. Divided visual attention can operate in parallel under conditions of low or moderate spatial interference between selected items, but strong interference engenders serial processing.
\end{abstract}

Keywords Visual selective attention · Cognitive architecture $\cdot$ Systems factorial technology

The typical visual environment contains too much information for the capacity-limited primate visual system to

\author{
Y. Yamani $(\bowtie) \cdot$ A. F. Kramer \\ Beckman Institute, University of Illinois at Urbana-Champaign, \\ 405 N. Mathews, \\ Urbana, IL 61801, USA \\ e-mail: yamani1@illinois.edu

\section{J. S. McCarley} \\ Flinders University, \\ Adelaide, South Australia \\ J. R. W. Mounts \\ The State University of New York at Geneseo, \\ Geneseo, NY, USA
}

process at once, a constraint that appears to arise from the neurophysiology of the extrastriate visual cortex (Kastner \& Ungerleider, 2000). Although receptive fields (RFs) in V1 are generally $2^{\circ}$ or less in diameter (Hubel \& Wiesel, 1968), extrastriate RFs can span many degrees of the visual field (Desimone \& Gross, 1979; Kastner et al., 2001; Smith, Singh, Williams, \& Greenlee, 2001). Because individual RFs are large enough to encompass two or more items simultaneously, a single neural response train can conflate the properties of multiple objects, producing an ambiguous or otherwise degraded representation (Kastner, De Weerd, Desimone, \& Ungerleider, 1998; Luck, Girelli, McDermott, \& Ford, 1997; Reynolds, Chelazzi, \& Desimone, 1999). This effect, a manifestation of the binding problem (Luck \& Beach, 1998; Reynolds \& Desimone, 1999; Treisman, 1996), limits the perceptual quality with which the objects in a crowded scene can be represented at one time (Tsotsos et al., 1995) and demands attentional mechanisms to isolate and prioritize behaviorally relevant items (Broadbent, 1958; Bundesen, 1990; Desimone \& Duncan, 1995; Sperling, 1960; Treisman \& Gelade, 1980).

From Broadbent's (1958) filter theory onward, models of attention have often assumed that the capacity limitations of the visual system are circumvented by resort to serial processing. Posner's (Posner, Davidson, \& Snyder, 1980) and Eriksen's (Eriksen \& Hoffman, 1973; Eriksen \& St. James, 1986) spatial selection models, for example, propose that regions of the visual field are attended in sequence by movements of a mental spotlight or lens. Both feature integration theory (Treisman \& Gelade, 1980) and the early versions of the guided search model (Wolfe, 1994; Wolfe, Cave, \& Franzel, 1989) posit an initial stage of parallel feature processing but hold that because the outputs of these front-end processes are impoverished (e.g., Treisman \& Schmidt, 1982; Wolfe \& Bennett, 1997), the accurate perception of multifeature objects requires serial selection via shifts of attentional focus. More biologically inspired 
accounts such as Desimone and Duncan's (1995) biased competition model (Desimone \& Duncan, 1995) and Tsotsos's (Tsotsos et al., 1995) selective tuning model propose an early wave of parallel activation, after which objects compete through reciprocal suppression for control of extrastriate neurons. Selection occurs when competition resolves, in a winner-take-all manner, in favor of a single object (e.g., Moran \& Desimone, 1985; Reynolds et al., 1999), effectively shrinking a set of RFs around the winning item. Data consistent with such models have shown behavioral and electrophysiological evidence of serial object selection in visual search tasks (Bricolo, Gianesini, Fanini, Bundesen, \& Chelazzi, 2002; Woodman \& Luck, 1999, 2003).

Alternative models, though, allow the possibility that attentional capacity might be allocated among multiple objects simultaneously without need for focal selection of individual stimuli. Bundesen's (1990) theory of visual attention, as one prominent instance, assumes a race between stimuli for access to visual short-term memory, with processing capacity distributed among objects in parallel on the basis of their match to an attentional target template. Latergeneration versions of guided search allow that processing may begin for different items at different times but can then proceed in parallel over multiple stimuli (Wolfe, 2003). Recent neurobiological models assume that attention modulates the responsiveness of extrastriate neurons to incoming signals, increasing gain for signals arising from attended stimuli and decreasing gain for signals arising from unattended stimuli (Ghose \& Maunsell, 2008; Womelsdorf, Anton-Erxleben, \& Treue, 2008). Serial processing results if gain for the unattended item reaches zero, but parallel processing obtains if gain for the unattended item remains positive. Such theoretic suggestions of parallel attentional processing are undergirded by empirical evidence of parallel selection in challenging visual search (Dosher, Han, \& Liu, 2004; McElree \& Carrasco, 1999; Pashler, 1987; Sung, 2008) and divided attention (Bundesen, Kyllingsbæk, \& Larsen, 2003; Hahn \& Kramer, 1998; Kyllingsbæk \& Bundesen, 2007; Miller \& Bonnel, 1994; Mordkoff \& Yantis, 1991; Mordkoff, Yantis, \& Egeth, 1990) tasks.

Of course, as the various empirical findings cited above suggest, the architecture of selection is unlikely to be fixed but probably varies with task demands and stimulus properties (Tsotsos, Rodríguez-Sánchez, Rothenstein, \& Simine, 2008). For instance, easy or moderately difficult perceptual judgments might allow parallel processing, while very difficult judgments may require serial selection of single objects (Bundesen, 1990; Egeth \& Dagenbach, 1991; Hogendoorn, Carlson, Van Rullen, \& Verstraten, 2010; Sung, 2008; Treisman \& Gelade, 1980). One further stimulus characteristic that might influence attentional architecture is the spatial relationship between attended items.
Contrary to the predictions of a unitary spotlight model, observers are often able to divide spatial attention between noncontiguous locations simultaneously (Hahn \& Kramer, 1998; Awh \& Pashler, 2000; Kramer \& Hahn, 1995). More surprisingly, performance often improves when attention is divided between noncontiguous locations. In one early demonstration of this phenomenon, Bahcall and Kowler (1999) asked participants to report the identity of two color-cued letters embedded in a ring of distractor letters and found that response accuracy increased as the distance between target letters grew. Control experiments confirmed that the effect was not the result of crowding or sensory masking or of a between-hemifield processing advantage (e.g., Banich, 1998; Sereno \& Kosslyn, 1991), suggesting instead a form of attentional interference at small values of target-target separation. Other research has produced similar findings (e.g., Caputo \& Guerra, 1998; McCarley, Mounts, \& Kramer, 2004; Mounts, 2000a, 2000b; Mounts \& Gavett, 2004).

Although somewhat counterintuitive, these findings accord with the premise of visual selective attention as a mechanism for resolving ambiguities in extrastriate representations (Desimone \& Duncan, 1995; Tsotsos et al., 1995). Because objects near one another in the visual field tend to share more RFs than objects distant from one another, the opportunity for reciprocal interference between attended stimuli increases with stimulus proximity (Desimone, 1998). Visual performance should therefore be poor when attention is divided between stimuli near one another in the visual field but improve as separation between the attended items increases. Consistent with this speculation, neurobiological indices of interference between attended objects decrease in strength as the separation between objects increases (Fuchs, Andersen, Gruber, \& Müller, 2008; Hillimire, Mounts, Parks, \& Corballis, 2009; Kastner et al., 2001).

This line of reasoning suggests that efficient parallel processing should be possible when attended stimuli are widely separated in the visual field and can therefore be represented by pools of RFs that are largely independent. When attended objects are in high proximity and fall largely within a common set of RFs, in contrast, performance should approach the predictions of a serial processing model. Studies using differing experimental techniques have provided converging evidence for this hypothesis. VanRullen and colleagues (VanRullen, Reddy, \& Fei-Fei, 2005) measured accuracy in tasks requiring subjects either to categorize a single stimulus presented in the visual periphery or to make same/different judgments of paired stimuli. Accuracy in the single-object task was used to derive performance predictions for the same/different task assuming unlimited-capacity parallel processing. Same-different judgments of two forms of stimuli, rotated letters and 
bisected discs, showed poor performance whether stimuli were near or far from one another in the visual field. Judgments for two other forms of visual objects, faces and natural scenes, however, showed no interference when stimuli were far from one another (in opposite quadrants of the visual field), consistent with parallel processing.

Another series of experiments (McCarley, Mounts, \& Kramer, 2007) tested for parallel processing of distant and proximate objects using a redundant targets task. Subjects viewed displays containing either a single target letter or a pair of redundant target letters, embedded among taskirrelevant fillers and were asked to make speeded judgments of target identity. Because paired targets were always redundant, subjects could render judgments using a firstterminating stopping rule; a response was possible as soon as either target had been identified (Colonius \& Vorberg, 1994). Under these conditions the standard serial model predicts equivalent mean response times (RTs) for single target and redundant targets trials, and a redundancy gain therefore gives evidence of parallel processing (Townsend, 1990; van der Heijden, 1975; van der Heijden, La Heij, \& Boer, 1983). RTs in fact showed a significant redundancy gain when target objects were distant from one another in the visual field and no redundancy gain when they were adjacent.

These data indicate that for at least some forms of stimuli, efficient parallel processing is possible when attended objects are widely separated but that processing efficiency declines as attended items are moved closer together. They leave open, though, the question of whether processing remains parallel at small separations or becomes serial, an ambiguity that arises from the problem of model mimicry (Townsend \& Ashby, 1983). VanRullen et al. (2005; see also Reddy \& VanRullen, 2007), for instance, found that psychophysical accuracy decreased when processing load increased from one item to two items in high proximity, a result consistent with serial processing. A parallel model in which processing efficiency declines as processing load increases predicts the same effect, however (Townsend, 1972, 1990). Thus, although a finding of invariant performance under increasing load disconfirms a conventional serial model, a finding of degraded performance under increasing load does not rule out a parallel model.

A similar constraint applies to the data of McCarley et al. (2007). As has been noted, the standard serial processing model predicts no redundancy gain under a first-terminating response rule. Unfortunately, a model in which processing is parallel but highly limited in capacity (Townsend \& Eidels, 2011; Townsend \& Nozawa, 1995) also predicts similar RTs for single- and redundant-target trials. The absence of a redundancy gain therefore fails to distinguish between parallel and serial architectures.
In sum, while decreasing spatial separation between attended stimuli can clearly degrade visual quality, data have yet to reveal whether or not this loss reflects a change in processing architecture. The present study addressed this question using the methodological approach known as systems factorial technology (SFT; Townsend \& Nozawa, 1995).

\section{Systems factorial technology}

An extension of Sternberg's (1969) additive factors methodology, SFT provides experimental and analytic methods for inferring the architecture of an information processing system (Townsend \& Nozawa, 1995; Townsend \& Wenger, 2004). Previous studies have employed SFT to investigate the architecture of speeded signal detection (Houpt \& Townsend, 2010; Townsend \& Nozawa, 1995), short-term memory search (Townsend \& Fifić, 2004), visual search (Fifić, Townsend, \& Eidels, 2008; Sung, 2008), face perception (Fifić \& Townsend, 2010), and saccade generation (Nozawa, Reuter-Lorenz, \& Hughes, 1994). To use SFT, the experimenter orthogonally manipulates processing difficulty for each of two target stimuli, producing four factorial conditions: low-difficulty-low-difficulty, high-difficulty-low-difficulty, low-difficulty-high-difficulty, and high-difficulty-high-difficulty. The manipulations are chosen to influence the processing stage of interest in the study. To study preattentive vision, for instance, the experimenter would design a manipulation to slow processing at the preattentive stage.

The manipulation of a given target is presumed to prolong the processing time for that target alone, an assumption of selective interference (Schweickert, 1978). Given this assumption, examination of interactions in the RT data can reveal the architecture of the information processing system under study (Schweickert \& Townsend, 1989; Townsend \& Nozawa, 1995). The mean interaction contrast (MIC) is defined as

$M I C=R T_{\mathrm{LL}}-R T_{\mathrm{LH}}-R T_{\mathrm{HL}}+R T_{\mathrm{HH}}$,

where $R T$ indicates mean $\mathrm{RT}$ and subscripts denote the levels of the stimulus difficulty for each of the two stimuli. Contingent on the operator's stopping rule, as discussed below, parallel and serial models offer different predictions for MIC (Schweickert \& Townsend, 1989).

For a stronger test, the analysis of the interaction contrast can be extended to the level of the RT distribution (Townsend, 1990). In this case, RTs in each experimental condition are aggregated to produce a cumulative distribution function (CDF), the complement of which is the survivor function, $S(t)$. The survivor 
interaction contrast (SIC; Houpt \& Townsend, 2010) is then defined as

$\operatorname{SIC}(\mathrm{t})=\mathrm{S}_{\mathrm{LL}}(\mathrm{t})-\mathrm{S}_{\mathrm{LH}}(\mathrm{t})-\mathrm{S}_{\mathrm{HL}}(\mathrm{t})+\mathrm{S}_{\mathrm{HH}}(\mathrm{t})$.

Again contingent on the operator's stopping rule, the predicted patterns of the SIC differ for the parallel and serial models. Note that the MIC, described above, is equal to the integral of the SIC over all nonnegative values of $t$.

Experiments by Sung (2008) and Fific, Townsend, and Eidels (2008) have employed SFT to demonstrate parallel visual search of letters and letter-like shapes. Stimuli in those experiments, however, were presented in the central visual field, within $2^{\circ}$ of visual angle of the fovea, while much past work on spatial interactions between attended objects has presented stimuli in the peripheral retinal. Because RFs in the central visual field tend to be smaller than those in the periphery (Felleman \& Van Essen, 1987; Gatass, Sousa, \& Gross, 1988; Smith et al., 2001), spatial interference between stimuli presented near the fovea may be relatively weak. More generally, neurobiological evidence suggests that spatial attentional interactions can operate differently in the fovea and periphery (Handy \& Khoe, 2005; Roberts, Delicato, Herrero, Gieslemann, \& Thiele, 2007). It is therefore not clear that the effects observed by Sung and by Fific, Townsend, and Eidels will hold in the visual periphery. The present experiments used SFT to examine processing architecture at large and small values of separation outside the fovea, employing stimuli similar to those of past psychophysical studies of competitive attentional interactions.

Both experiments employed a compound discrimination task in which subjects were asked to search for a target letter from among a pair of colored-cued objects surrounded by gray filler objects. Color cues were chosen to allow preattentive detection (pop-out) of the cued objects. However, the presence of the fillers disallowed fully preattentive search performance (cf. McCarley, Yamani, Mounts, \& Kramer, 2012). To perform the search task, rather, subjects were required to bind the color cues to their shapes and then resolve those shapes well enough to discriminate targets from distractors. Processing difficulty was manipulated through changes to the discriminability of nontarget shapes relative to target shape (Fifić, Townsend, \& Eidels, 2008; Sung, 2008); the target was a letter $L$ and nontargets were the letters $O$ (high discriminability) and $T$ (low discriminability). Manipulations of difficulty should thus have influenced processing beyond the level of preattentive feature detection, at the attentive stage of feature integration and object recognition (Treisman \& Gelade, 1980; Wolfe \& Bennett, 1997). Cued items were presented either adjacent to one another or at diametrically opposite locations on either side of the fovea.
The target search task was embedded within a go/nogo response paradigm that imposed an exhaustive stopping rule for response execution. More specifically, subjects were asked execute a keypress to signal a targetabsent response and to withhold the keypress to signal a target-present response. Before executing a keypress response, therefore, subjects were required to identify both cued items as nontargets. Under these conditions, a parallel processing model predicts that the MIC will be negative, and

$\operatorname{SIC}(\mathrm{t}) \leq 0$ for all ts.

A serial processing model predicts that the $\mathrm{MIC}=0$ and $\operatorname{SIC}(\mathrm{t}) \leq 0$ for $0<\mathrm{t}<\mathrm{c}$, and $0 \leq \operatorname{SIC}(\mathrm{t})$ for $\mathrm{c}<\mathrm{t}$,

where $c$ is a time within a range of RTs (for details, see Houpt \& Townsend, 2010; Townsend \& Nozawa, 1995). In other words, the serial model predicts that the SIC will show a negative deflection followed at some time $c$ by a positive deflection. The prediction that MIC $=0$ adds the further constraint that the areas under the positive and negative regions of the SIC will be equivalent. ${ }^{1}$

Experiment 1 examined the effects of spatial separation on attentional architecture under conditions in which the spacing between attended and filler stimuli was relatively sparse. Experiment 2 employed the same procedure but increased the number of fillers and decreased the spacing between stimuli to strengthen the interference between attended items.

\section{Experiment 1}

The stimuli in Experiment 1 were the letters $\mathrm{O}, \mathrm{T}$, and $\mathrm{L}$, and the subjects' task was to judge whether either of two color-cued items presented among six gray fillers was a target letter L. Stimulus items were arranged in a circle around the central fixation point, with two items in each quadrant of the visual field. Cued items on each trial appeared either in low proximity (Fig. 1a) or in high proximity (Fig. 1b), in an effort to produce conditions of low and high spatial interference, respectively. MIC and SIC for the low- and high-proximity conditions were analyzed for evidence of serial or parallel processing.

\footnotetext{
${ }^{1}$ An alternative class of parallel models, known as coactive (Miller, 1982; Townsend \& Nozawa, 1995), makes predictions different from those of either a conventional parallel or a serial model. Because none of the present data gave evidence of coactivation, discussion will focus on conventional parallel and serial models.
} 
Fig. 1 Illustrations of the stimulus displays and procedure in Experiment 1. a Sample display from the low-proximity condition. b Sample display from the high-proximity condition. c Timeline of events within a trial a

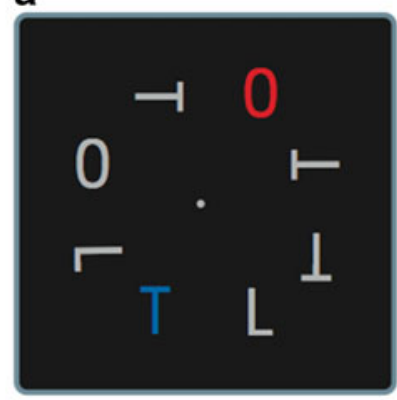

b

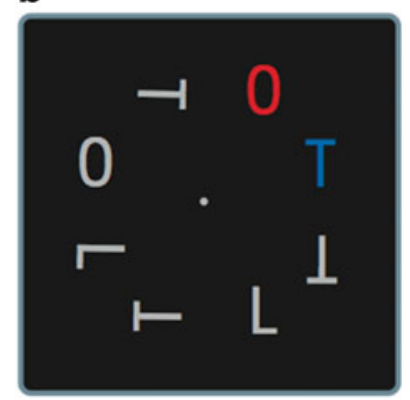

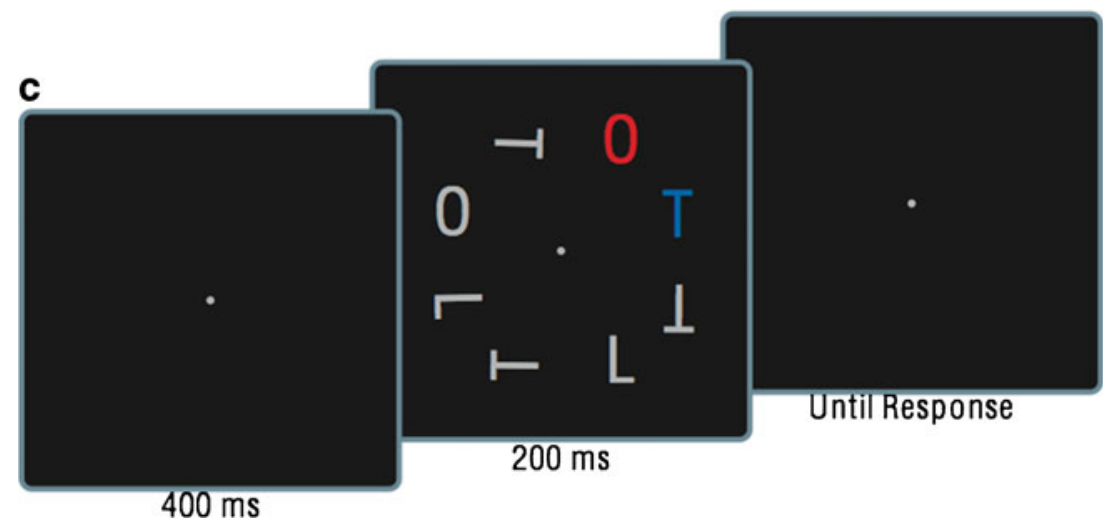

Method

Subjects

Subjects were 14 young adults ( 9 males, mean age $=$ 22.5 years) from the community of the University of Illinois. All subjects had normal or corrected-to-normal visual acuity and normal color vision and were paid for participation.

\section{Apparatus}

The stimuli were presented on a 19-in. CRT monitor with a resolution of $1,024 \times 768$ pixels and a frame rate of $75 \mathrm{~Hz}$. The experiment was controlled by E-Prime 1.1 (Psychology Software Tools, Pittsburgh, PA). Responses were made via a response box. Subjects viewed the screen at distance of $57 \mathrm{~cm}$ held fixed by a chinrest. The experiment was conducted in a quiet room with dimmed lights.

\section{Stimuli}

Each display contained eight letters, T, O, or $\mathrm{L}, 1.38^{\circ} \times$ $1.38^{\circ}$ and drawn in a stroke of $.07^{\circ}$, each randomly rotated by $0^{\circ}, 90^{\circ}, 180^{\circ}$, or $270^{\circ}$. Letters were equally spaced about the perimeter of an imaginary circle of radius $6.84^{\circ}$, with two stimuli in each quadrant of the visual field, one $\pm 22.5^{\circ}$ from the vertical midline and one $\pm 22.5^{\circ}$ from the horizontal midline. One item in every display was drawn in red $(9.0 \mathrm{~cd} /$ $\left.\mathrm{m}^{2}, x=.64, y=.33\right)$, and another in blue $\left(10.0 \mathrm{~cd} / \mathrm{m}^{2}, x=\right.$ $.15, y=.07)$. The remaining items were drawn in gray $\left(6.5 \mathrm{~cd} / \mathrm{m}^{2}\right)$. Stimuli were presented on a black background with a $0.17^{\circ} \times 0.17^{\circ}$ fixation cross at its center. The identities of the red and blue items $(\mathrm{T}, \mathrm{O}$, or $\mathrm{L})$ varied across trials as described below. The identities of the gray items were chosen randomly and independently.

\section{Procedure}

The two colored letters in each display were designated cued items, and the gray letters were designated fillers. In the highproximity condition, the cued items appeared adjacent to one another within the same quadrant of the visual field. In the low-proximity condition, they appeared four positions apart, at diametrically opposite points on either side of fixation.

Subjects performed a go/no-go task requiring them to withhold a response if either of the cued items within a display was an L (no-go trials) and to execute a keypress response if neither of the cued items was an $\mathrm{L}$ (go trials). They were instructed to ignore the fillers and to make their responses as quickly and accurately as possible. Processing difficulty was manipulated by varying the similarity of the nontarget cued items to the target letter L, using the O letters as low-similarity (i.e., low-difficulty) nontargets and the T letters as high-similarity nontargets. On no-go trials, only one of the two cued items was an L. On go trials, therefore, the subject was required to process both of the cued items in order to ensure that neither was an L. 
Figure 1c presents the stream of events within a trial. A trial started with a 500-ms blank screen, which was followed by a $400-\mathrm{ms}$ fixation screen and then the stimulus display. On practice trials, stimuli remained visible until a response was executed or a time-out duration of $2,500 \mathrm{~ms}$ had elapsed. On experimental trials, the duration of the stimulus display was limited to $200 \mathrm{~ms}$ in order to discourage eye movements. A failure to respond before the time-out was classified as an error. At the end of each trial, the subjects received a 750-ms feedback message of "+" for a correct response or " $\mathrm{x}$ " for an incorrect response. The next trial began automatically after a delay of $500 \mathrm{~ms}$. Each subject completed two experimental sessions within the course of no more than 3 days. Each session comprised 1 block of 40 practice trials followed by two cycles of 16 blocks of 40 experimental trials each. The experimental trials within a session included 128 no-go trials and 512 go trials. The 512 go trials were divided equally between all factorial combinations of red item identity ( $\mathrm{O}$ vs. $\mathrm{T})$, blue item identity $(\mathrm{O}$ vs. $\mathrm{T})$, and proximity between cued items (low vs. high). The order of trials within a block was random. Subjects were free to rest between blocks.

\section{Results}

Data were excluded from 4 subjects whose error rate for no-go trials (i.e., false go rates) exceed $30 \%$. Analyses including these data produced a pattern of effects identical to that reported below. See below for further discussion of error rates and their relationship to the RT analyses.

For preliminary analysis, RTs were submitted to a withinsubjects ANOVA with the identity of the red item, the identity of the blue item, and the proximity between cued items as within-subjects factors. Tests of architecture were then conducted separately for each level of proximity, as described below. Error rates were analyzed as described below. Data for incorrect responses were excluded from analyses of RT.

\section{$R T s$}

Figure 2 presents mean RTs for low-proximity (left panel) and high-proximity (right panel) conditions. RTs were longer when cued items were in high proximity $(\mathrm{M}=313 \mathrm{~ms}$ vs. $\mathrm{M}=297 \mathrm{~ms}), F(1,9)=11.72, p<.01, M S E=434.50$, $\eta_{\mathrm{p}}^{2}=.57$, confirming that the proximity manipulation modulated the interference between cued items as expected. RTs were also longer when the cued items were Ts than when they were Os ( $\mathrm{M}=324 \mathrm{~ms}$ vs. $\mathrm{M}=286 \mathrm{~ms}), F(1,9)=56.30$, $p<.01, M S E=594.00, \eta_{\mathrm{p}}^{2}=.86$ for red item identity; $F(1$,
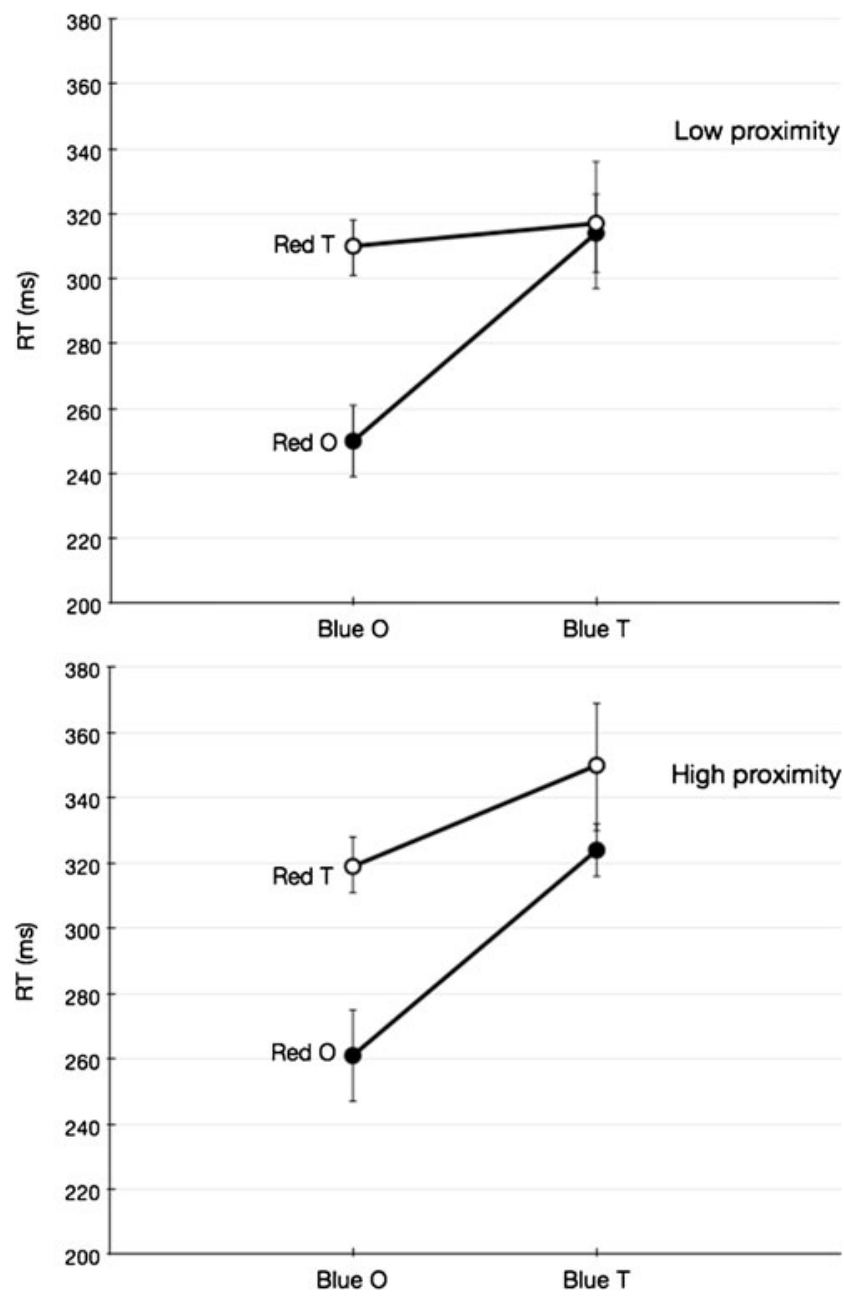

Fig. 2 Mean response times (RTs) for the low-proximity (top) and high-proximity (bottom) conditions in Experiment 1. Error bars in all figures of mean RTs represent within-subjects $95 \%$ confidence intervals based on the method of Cousineau (2005) and Morey (2008)

9) $=54.19, p<.01$, MSE $=497.88, \eta_{\mathrm{p}}^{2}=.86$ for blue item identity, confirming that the manipulation of target-nontarget similarity was effective. The two-way interaction of red and blue item identity, collapsing across levels of proximity, was subadditive and statistically reliable, $F(1,9)=32.49$, $p<.01, M S E=307.16, \eta_{\mathrm{p}}^{2}=.78$. A three-way interaction, however, $F(1,9)=7.91, p=.02, M S E=96.37, \eta_{\mathrm{p}}^{2}=.46$, qualified this result, indicating that the interaction of red and blue item identity was weaker when cued stimuli were in high proximity. These interactions are discussed further as tests of architecture, below.

\section{Tests of architecture: MIC}

Analyses of system architecture were conducted separately for low- and high-proximity conditions. For these, data were submitted to two-way within-subjects ANOVAs with the identity of the red cued item and 
the identity of the blue cued item as factors. MIC was calculated with the formula

$M I C=R T_{\mathrm{OO}}-R T_{\mathrm{OT}}-R T_{\mathrm{TO}}+R T_{\mathrm{TT}}$,

where subscripts indicate distractor identities.

RTs for judgments of low-proximity items were longer when the cued items were Ts than when they were Os, $F(1$, 9) $=43.86, p<.01, M S E=282.28, \eta_{\mathrm{p}}^{2}=.83$ for red item identity; $F(1,9)=38.65, p<.01, M S E=254.34, \eta_{\mathrm{p}}^{2}=.81$ for blue item identity, confirming that the manipulation of target-nontarget similarity was effective in the lowproximity conditions. Data also evinced a significant interaction of red item identity and blue item identity reflecting a negative mean MIC (MIC $=-57,95 \% \mathrm{CI}[-87.58,-43.03]$ ), $F(1,9)=25.11, p<.01, M S E=323.79, \eta_{\mathrm{p}}^{2}=.73$. As was discussed above, a negative MIC under an exhaustive stopping rule indicates parallel processing. These data thus generalize earlier findings of parallel attentional processing under conditions of low spatial interference between attended items.

RTs for judgments of high-proximity items produced a similar pattern of effects: RTs were longer when cued items were Ts than when they were Os, $F(1,9)=47.23, p<.01$, $M S E=459.79, \eta_{\mathrm{p}}^{2}=.84$ for red item identity; $F(1,9)=$ $55.29, p<.01, M S E=320.67, \eta_{\mathrm{p}}^{2}=.86$ for blue item identity, and evinced a reliable interaction indicating a negative mean MIC (MIC $=-32,95 \% \mathrm{CI}[-47.49,-25.38]), F$ $(1,9)=32.76, p<.01, M S E=437.22, \eta_{\mathrm{p}}^{2}=.78$. Results indicate that processing architecture remained parallel as spatial interference between attended items increased.

\section{Tests of architecture: SIC}

For analysis of SIC distributions, RTs from each experimental condition were sorted into $10-\mathrm{ms}$ bins, and the SIC was calculated by bin using the formula

$S I C(t)=S_{\mathrm{OO}}(t)-S_{\mathrm{OT}}(t)-S_{\mathrm{TO}}(t)+S_{\mathrm{TT}}(t)$,

where subscripts again indicate distractor identities.

Figure 3 presents the survivor functions for low- (top panel) and high-proximity conditions (bottom panel). A critical premise for systems factorial analysis of RT distributions is the assumption of stochastic dominance, which requires that less discriminable stimulus pairs do not produce lower cumulative survival probability at any time than do more discriminable pairs (Townsend \& Nozawa, 1995). One-sided Kolmogorov-Smirnov tests (Houpt \& Townsend, 2010) showed no violations of this assumption.

Figure 4 presents SICs for low- (top panel) and highproximity conditions (bottom panel). As the $95 \%$ confidence intervals make clear, SIC values were statistically less than or equal to 0 across all time bins for both conditions, matching the predictions of a parallel model. Although SIC
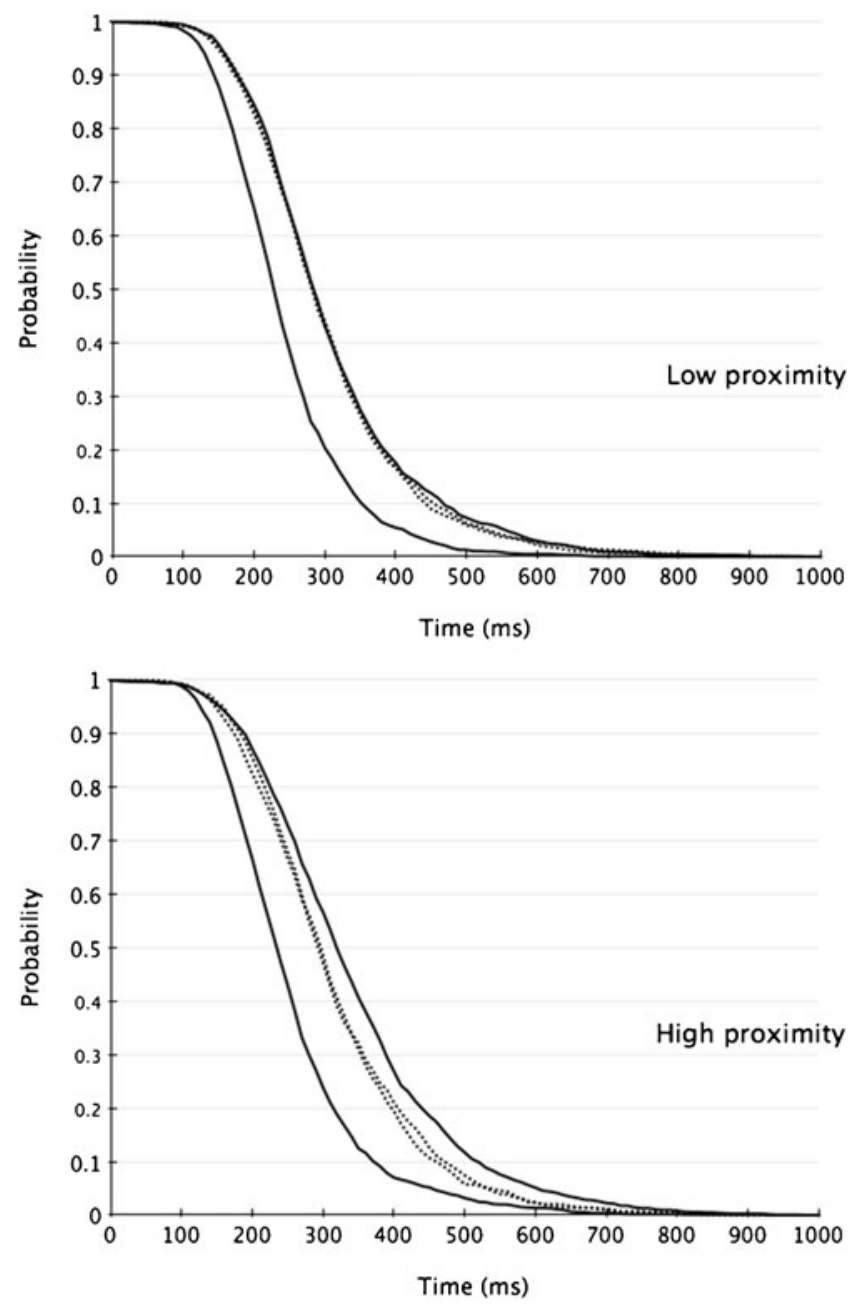

Fig. 3 Mean survivor functions for the low-proximity (top) and highproximity (bottom) conditions in Experiment 1. Leftmost solid lines indicate the $\mathrm{O}-\mathrm{O}$ condition; dotted lines indicate the $\mathrm{O}-\mathrm{T}$ and $\mathrm{T}-\mathrm{O}$ conditions; rightmost solid lines indicate the $\mathrm{T}-\mathrm{T}$ condition

values for the high-proximity condition numerically exceeded 0 after roughly $450 \mathrm{~ms}$, the area under this positive deflection was far more modest than predicted by a serial model, and in no time bin was the difference from 0 statistically significant. The small positive deflection of the highproximity SIC function therefore seems likely to have been the result either of statistical noise or, as is discussed below, of a small number of serial processing trials mixed within a distribution that was predominantly parallel.

For further analysis, SIC data from individual subjects were submitted to a statistical test developed by Houpt and Townsend (2010). The Houpt-Townsend test asks whether the maximum or minimum value of an empirical SIC deviates statistically from zero. With an alpha level of .05, the critical value for a deviation in either direction is

$D_{\text {crit }}=\sqrt{\frac{\log (.05)}{-2 N}}$ 

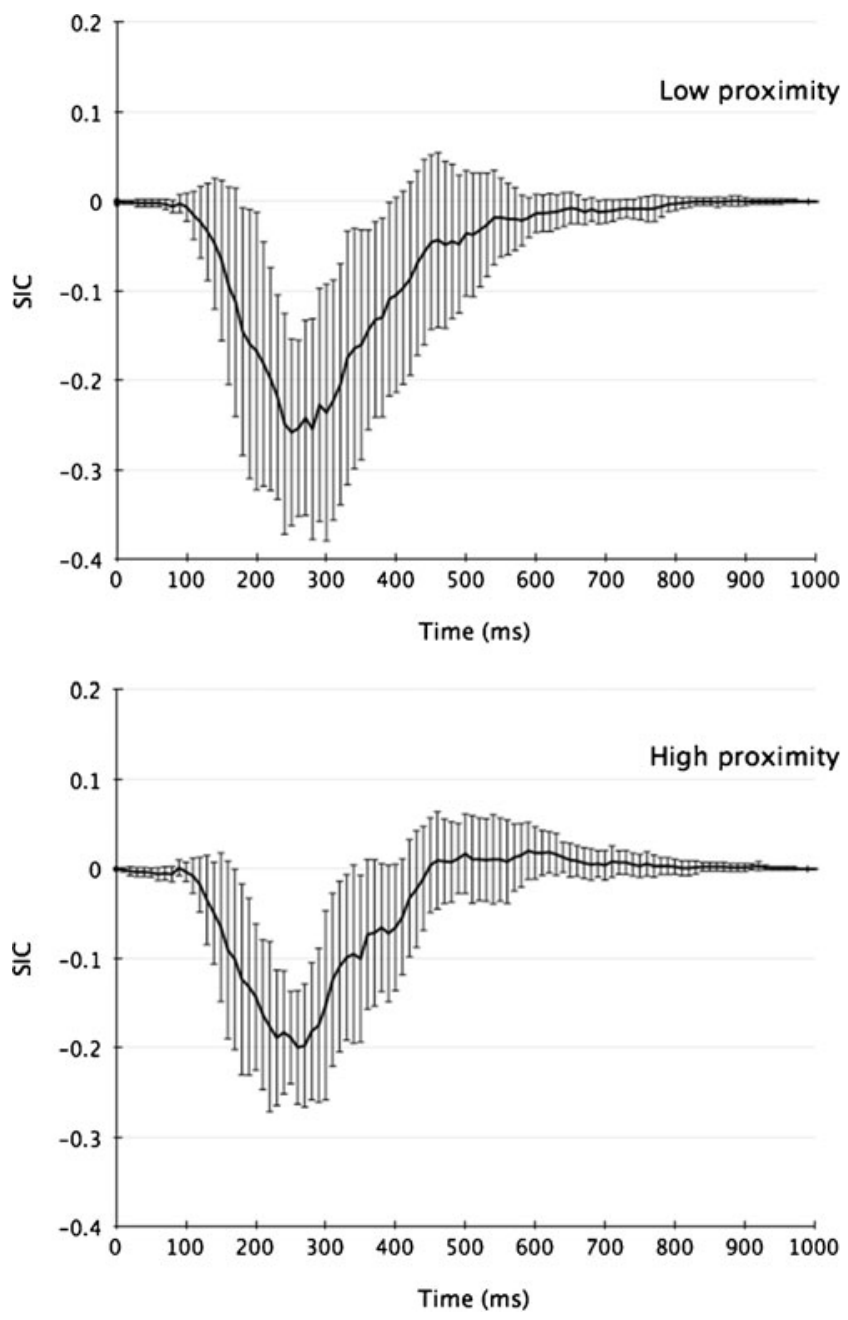

Fig. 4 Mean survivor interaction contrasts (SICs) for the lowproximity (top) and high-proximity (bottom) conditions in Experiment 1. Error bars in all figures of SICs represent between-subjects $95 \%$ confidence intervals

where $N$ is the number of trials in each factorial condition. The relevant tests for present purposes ask whether minimum negative or maximum positive SIC values differed statistically from zero. All subjects showed minimum SIC values significantly less than 0 in both the low- and highproximity conditions, consistent with predictions of a parallel model, and none showed a maximum SIC value significantly greater than 0 , contrary to the predictions of a serial model.

\section{Error rates}

Go trials produced low error rates (i.e., failure-to-go rates), with mean values of $1.2 \%$ and $1.5 \%$ under conditions of low and high proximity between cued items, respectively. Analysis of arcsine-transformed values, using an ANOVA identical to that used for preliminary analysis of RTs, produced only one significant effect, indicating a slightly higher error rate when a red distractor was $\mathrm{T}(1.9 \%)$ than when it was an $\mathrm{O}(0.8 \%), F(1,9)=12.81, p<.01, M S E=.006, \eta_{\mathrm{p}}^{2}=.59$.

Error rates for no-go trials (i.e., false-go rates) were higher, showing mean values of $11.5 \%$ for judgments of low-proximity items and $14.2 \%$ for judgments of highproximity items. For analysis, arcsine-transformed values were submitted to a $2 \times 2$ ANOVA with proximity between cued items and identity of the nontarget cued item (O or T) as within-subjects factors. (Recall that the second cued item on no-go trials was always a target L.) Analysis produced no significant main effects $(p \mathrm{~s}>.15)$ but a significant interaction, $F(1,9)=6.01, p=.04, M S E=.003, \eta_{\mathrm{p}}^{2}=.40$. Post hoc $t$-tests indicated that $\mathrm{O}$ and $\mathrm{T}$ distractors produced similar false-go rates when cued items were in high proximity ( $13.8 \%$ vs. $14.5 \%$, respectively), $t(9)=0.68, p=.51$, but that $\mathrm{O}$ distractors produced moderately higher false-go rates than did $\mathrm{T}$ distractors when items were in low proximity ( $13.4 \%$ vs. $9.6 \%$, respectively), $t(9)=2.32, p=.05$.

Note that although the error rates for no-go trials were higher than is conventional in RT studies, SFT's qualitative RT predictions are robust against error rates of $30 \%$ or more (Fifić, Nosofsky, \& Townsend, 2008). The level of errors observed here thus did not threaten to bias the RT effects. Converging evidence for this conclusion comes from the finding that effects consistent with parallel processing was almost perfectly consistent across individual subjects, as described above, despite the fact that mean error rates varied across subjects from a low of $5 \%$ to a high of $25 \%$.

In total, data give no evidence of speed-accuracy tradeoffs across experimental conditions and no evidence that the rate of error responses distorted the results of RT analyses.

\section{Discussion}

Mean RTs in Experiment 1 increased when cued stimuli were moved from opposite quadrants of the visual field to adjacent positions within same quadrant, demonstrating the expected pattern of spatial interference between attended objects. Evidence of parallel processing, however, obtained across both low and high levels of proximity between the attended items. The data of Experiment 1 thus replicate earlier findings of parallel attentional processing under conditions of low spatial interference and extend those results by demonstrating that selection can remain parallel under conditions of higher spatial interference.

Nonetheless, the data allow the possibility that a still stronger manipulation of interference might induce serial processing. The effect of spatial interference in Experiment 1 was statistically significant but modest; mean RT differed by only $16 \mathrm{~ms}$ between the low- and high-proximity conditions. Furthermore, the MIC was significantly smaller for judgments of high-proximity stimuli $(M=-32 \mathrm{~ms})$ than for judgments of low-proximity stimuli $(M=-57 \mathrm{~ms})$, and the 
negative peak of the SIC function was less pronounced. Finally, the SIC for high-proximity judgments showed a numeric, although statistically nonsignificant, positive deflection following the more obvious and statistically significant negative deflection. These effects together suggest that although interference under high-proximity conditions was too weak to entirely prevent parallel selection, it might have induced serial processing on a small proportion of trials, attenuating the markers of parallel selection.

Phrased differently, the results imply that performance in Experiment 1 may have reflected a cross-trial mixture distribution of parallel and serial processing, where the proportion of trials involving serial processing was near zero under conditions of low spatial interference but increased under higher interference. This suggests, in turn, that a stronger manipulation of interference might produce more consistently serial processing. Experiment 2 tested this possibility.

\section{Experiment 2}

Experiment 2 employed stimuli and a procedure similar to those in Experiment 1 but increased the stimulus density, adding an additional eight fillers to each display and concomitantly reducing the spatial separation between stimuli. As an increase in stimulus density tends to increase the difficulty of attentional selection (Cohen \& Ivry, 1991; Franconeri, Alvarez, \& Enns, 2007; McCarley et al., 2012), interference in the present experiment should be stronger than in the first.

\section{Method}

\section{Stimuli}

Stimuli were identical to those in Experiment 1, except that each display contained 16 letters, 2 cued items and 14 gray items (Fig. 5). The 2 cued items again appeared adjacent to one another in the same quadrant of the visual field under high-proximity conditions and appeared at diametrically opposite locations on either side of fixation under lowproximity conditions. In both cases, stimuli were constrained to ensure that cued items both appeared at one of the two middle positions within a quadrant of the visual field (i.e., cued items never appeared adjacent to either the vertical or the horizontal midline of the visual field).

\section{Subjects}

Fourteen young adults $(7$ males, mean age $=20.6$ years $)$ participated as subjects. All had normal or corrected-tonormal visual acuity and normal color vision. None had participated in Experiment 1.

\section{Procedure}

The procedure was identical to that in Experiment 1.

Results

Data treatment and analyses were identical to those in Experiment 1. Analyses excluded data from 1 subject whose error rate for no-go trials exceeded $30 \%$. Analyses including these data produced a pattern of effects identical to that reported below.

\section{$R T s$}

Figure 6 presents mean RTs for the low-proximity (left panel) and high-proximity (right panel) conditions. As was expected, RTs were longer under conditions of high proximity between attended items ( $M=300 \mathrm{~ms}$ vs. $M=279 \mathrm{~ms})$, $F(1,12)=43.6, p<.01, M S E=271.50, \eta_{\mathrm{p}}^{2}=.78$, and were longer when the cued items were Ts than when they were Os $(M=310 \mathrm{~ms}$ vs. $M=268 \mathrm{~ms}), F(1,12)=98.29, p<.01$, $M S E=444.44, \eta_{\mathrm{p}}^{2}=.89$ for red items; $F(1,12)=112.68$,
Fig. 5 Sample stimulus displays from the lowproximity (a) and highproximity (b) conditions in Experiment 2 a

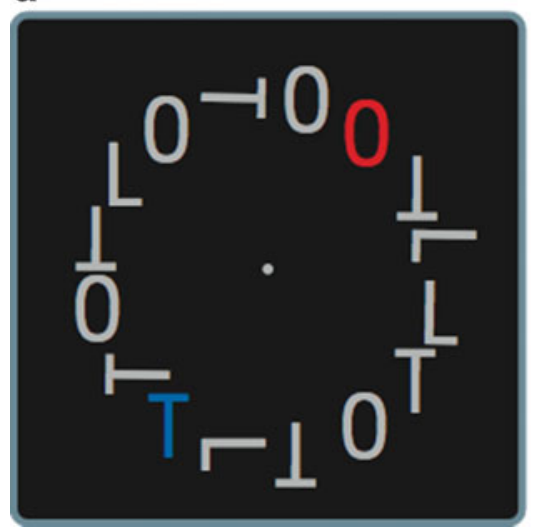

b

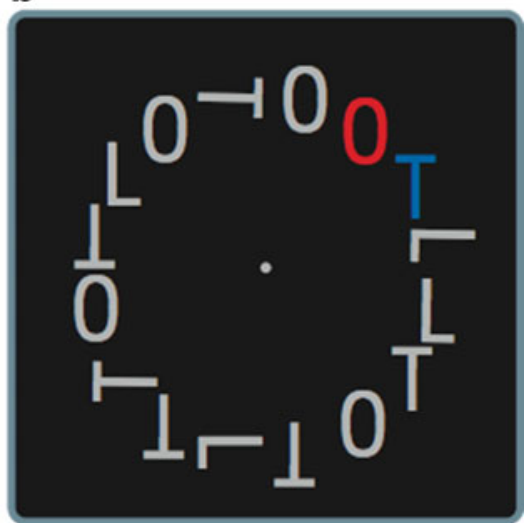



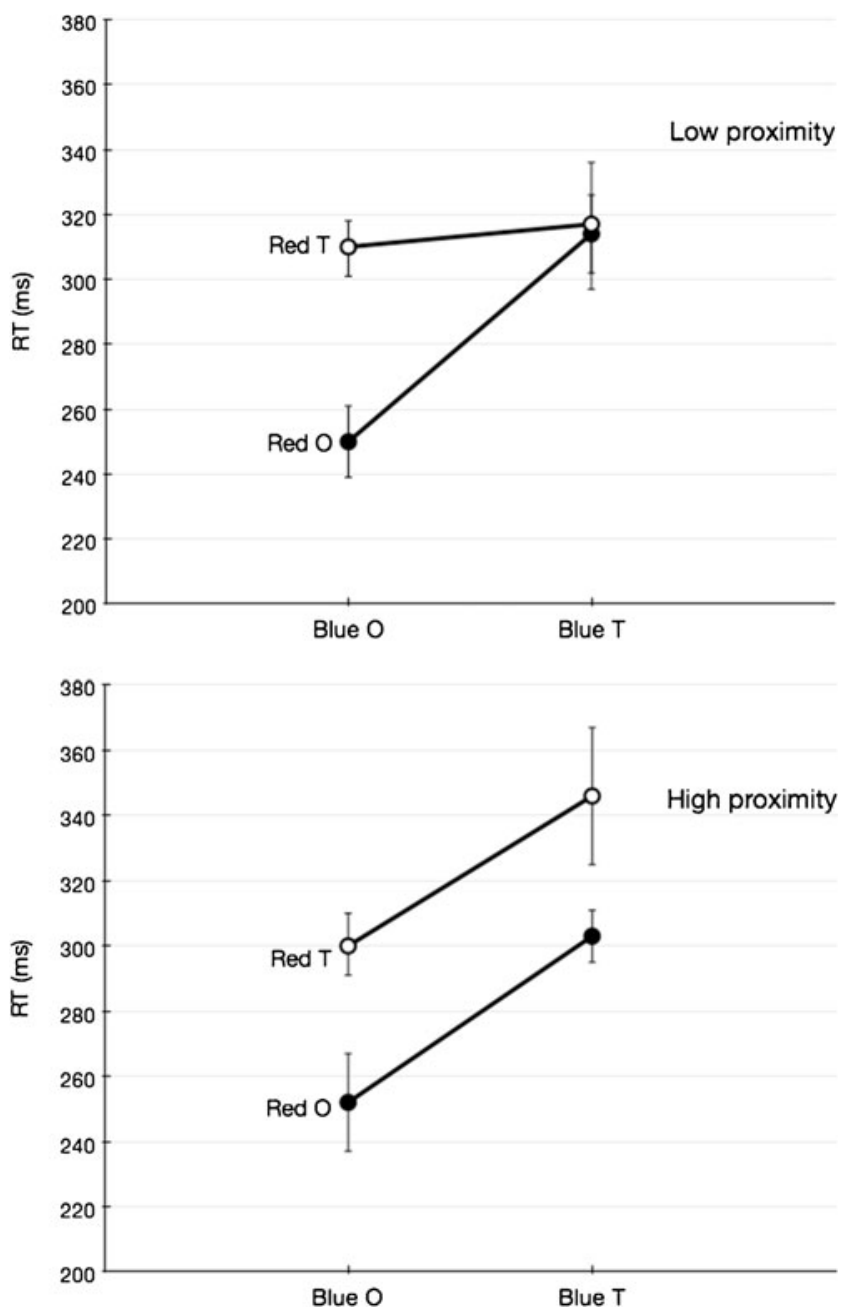

Fig. 6 Mean response times (RTs) for the low-proximity (top) and high-proximity (bottom) conditions in Experiment 2

$p<.01, M S E=429.77, \eta_{\mathrm{p}}^{2}=.90$ for blue items. As in Experiment 1, the two-way interaction between red item identity and blue item identity was significant, $F(1,12)=$ $5.20, p=.04, M S E=417.98, \eta_{\mathrm{p}}^{2}=.30$, but was qualified by a three-way interaction, $F(1,12)=7.95, p=.01, M S E=$ $130.25, \eta_{\mathrm{p}}^{2}=.39$. These interactions are discussed further as tests of architecture, below.

\section{Tests of architecture: $M I C$}

MICs were calculated as in Experiment 1. Under lowproximity conditions, RTs were longer when cued items were Ts than when they were Os, $F(1,12)=179.15, p<$ $.01, M S E=82.99, \eta_{\mathrm{p}}^{2}=.93$ for red item identity; $F(1,12)=$ $134.79, p<.01, M S E=159.80, \eta_{\mathrm{p}}^{2}=.91$ for blue item identity, confirming that the manipulation of target-distractor similarity was effective. A statistically reliable interaction indicated a negative mean $\mathrm{MIC}$ (MIC $=-30.9,95 \% \mathrm{CI}$ $[-46.58,-15.24]),[F(1,12)=25.51, p<.01, M S E=$ $121.73, \eta_{\mathrm{p}}^{2}=.68$, consistent with parallel processing.
Under high-proximity conditions, RTs were longer when cued items were Ts than when they were Os, $F(1,12)=$ $63.35, p<.01, M S E=475.92, \eta_{\mathrm{p}}^{2}=.84$ for red item identity; $F(1,12)=60.81, p<.01, M S E=444.71, \eta_{\mathrm{p}}^{2}=$ .83 for blue item identity. Critically, however, the interaction of red and blue item identity fell well short of the statistical significance, indicating an MIC that did not differ statistically from zero (MIC $=-5.6,95 \% \mathrm{CI}[-34.99,23.66]), F<$ 1 , n.s., and thus implying serial processing.

\section{Tests of architecture:SIC}

SICs were calculated as in Experiment 1. Figure 7 presents the survivor functions for low-proximity (top panel) and highproximity (bottom panel) conditions. Figure 8 presents the corresponding SICs. Survivor functions in both cases are ordered appropriately, and one-sided Kolmogorov-Smirnov tests showed no violations of the assumption of stochastic dominance.
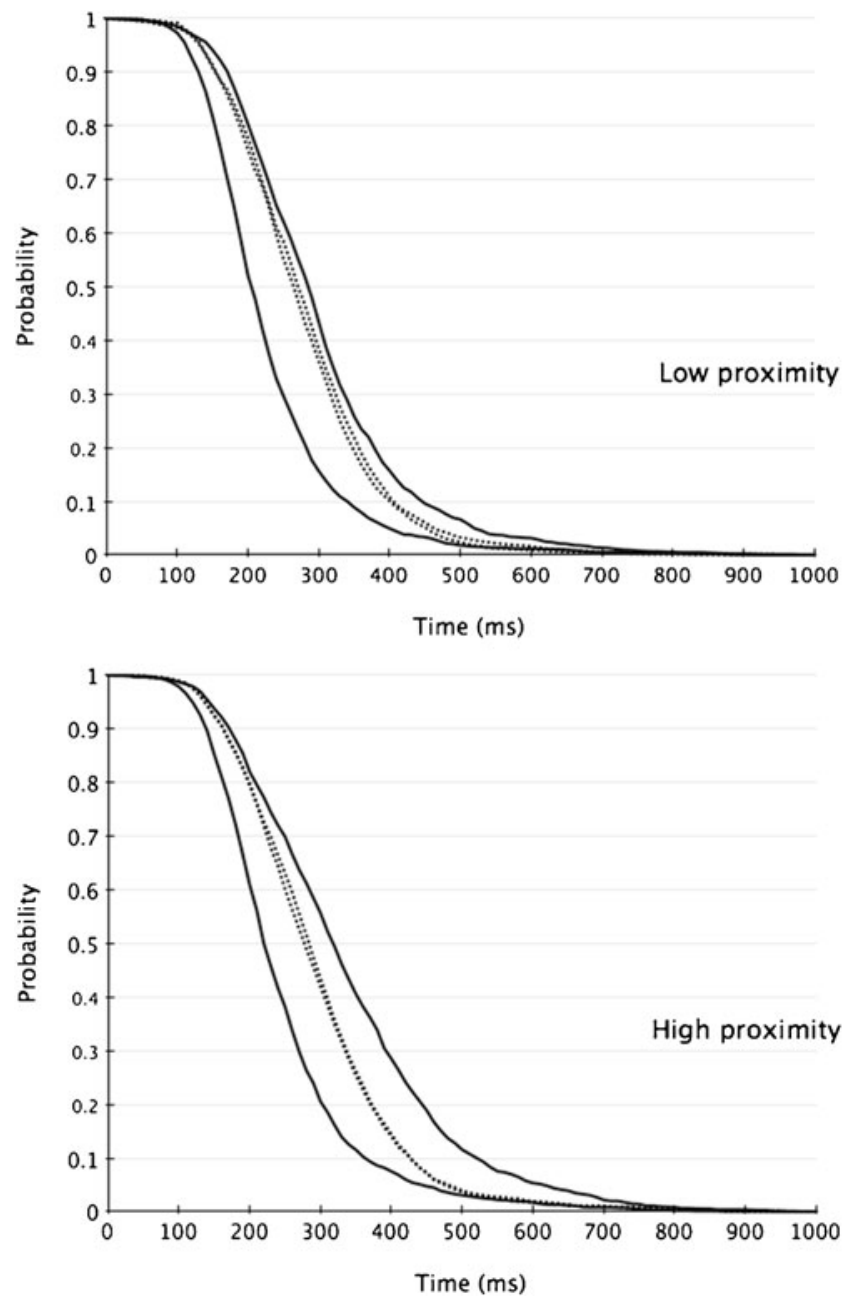

Fig. 7 Mean survivor functions for the low-proximity (top) and highproximity (bottom) conditions in Experiment 2. Leftmost solid lines indicate the $\mathrm{O}-\mathrm{O}$ condition; dotted lines indicate the $\mathrm{O}-\mathrm{T}$ and $\mathrm{T}-\mathrm{O}$ conditions; rightmost solid lines indicate the $\mathrm{T}-\mathrm{T}$ condition 

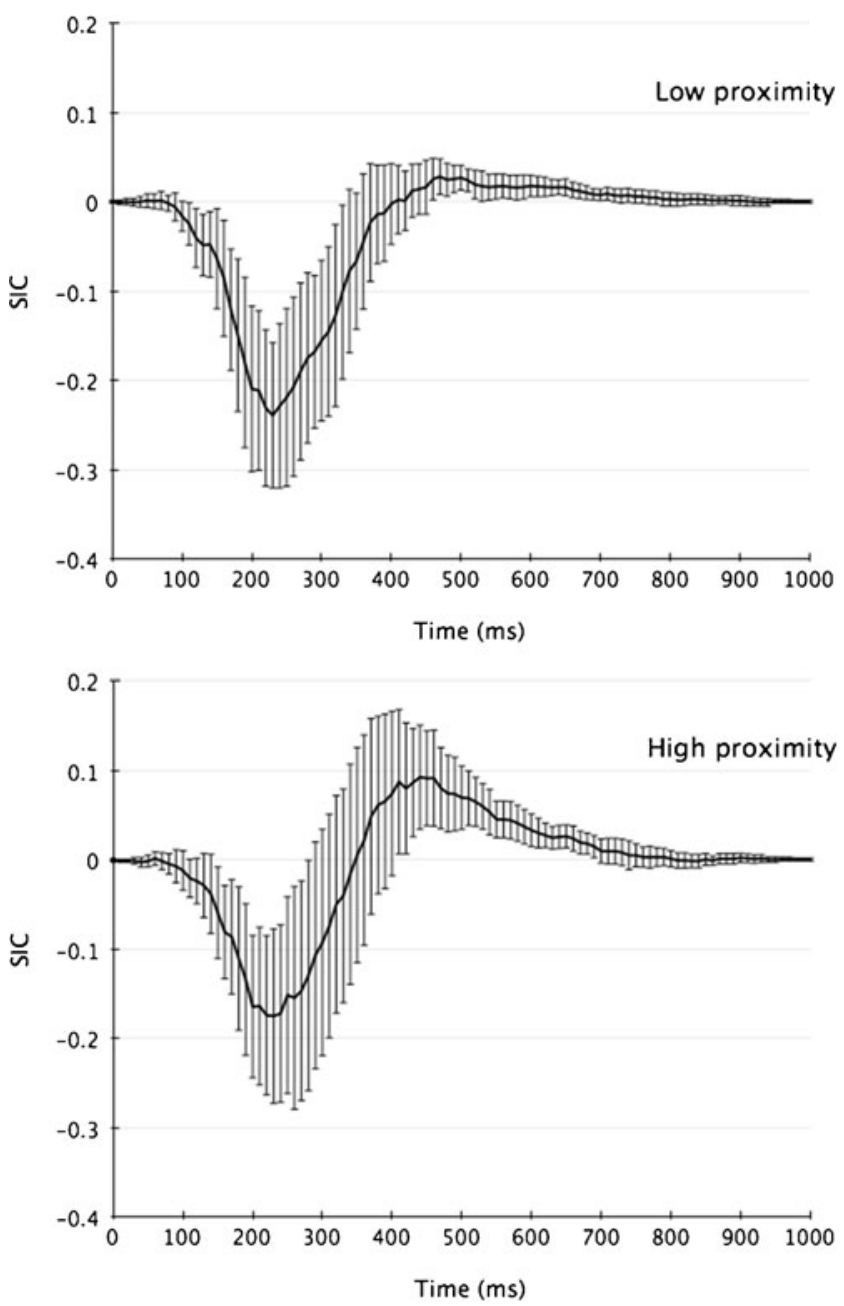

Fig. 8 Mean survivor interaction contrasts (SICs) for the lowproximity conditions (top) and for the high-proximity conditions (bottom) in Experiment 2

The mean SIC function for low-proximity conditions showed a large and significant negative deflection followed by a weak positive deflection beginning at roughly $450 \mathrm{~ms}$. Confidence intervals on the SIC suggest that the mean positive values significantly exceeded 0 in some time bins, violating the predictions of the parallel model. Contrary to the predictions of a serial model, however, the area under the positive portion of the SIC was substantially smaller than the area under the negative portion. Furthermore, while 13 of 13 individual subjects showed a significant negative minimum SIC value, as assessed by the Houpt and Townsend (2010) tests, none showed a significant positive maximum value. As with the high-proximity SIC in Experiment 1, therefore, the small positive deflection of the lowproximity SIC function in the present experiment was likely the result either of statistical noise or of a small number of serial processing trials mixed within a distribution that was generally parallel.
In contrast, the mean SIC function for judgments of highproximity stimuli gave evidence of serial selection, showing a significant negative deflection followed by a significant positive deflection, with the areas under the negative and positive portions of the SIC being similar (as confirmed by the analysis of the MIC described above). Analyses of individual subjects' data using the Houpt-Townsend tests produced a less clear-cut pattern. Two subjects produced maximum and minimum SIC values both differing statistically from 0 , conforming strongly to the predictions of a serial model, while 3 other subjects showed significantly positive maximum SIC values, violating the predictions of a parallel model. Seven additional subjects showed significantly negative minimum SIC values, while individual SICs for the remaining subjects showed no significant deviations from zero in either direction. These effects may reflect meaningful individual differences between subjects or may more simply indicate that statistical power at the level of individual SICs was too low to detect deviations from zero in some subjects.

\section{Error rates}

Go trials gave error rates of $1.2 \%$ and $2.8 \%$ under conditions of low and high proximity between cued items, respectively. Analysis of arcsine-transformed values, using an ANOVA identical to that used for preliminary analysis of RTs, revealed significant effects of cued item proximity, red item identity, and blue item identity, along with an interaction of proximity and blue item identity $\left(p<.05, \eta_{\mathrm{p}}^{2}>.30\right.$, for all four effects), all in the direction consistent with the corresponding RT means. Mean error rate for go trials did not exceed $5.25 \%$ in any condition, however.

Mean error rate for no-go trials was $19.1 \%$ for judgments of low-proximity items and $24.3 \%$ for judgments of highproximity items. An analysis identical to that used in Experiment 1 indicated higher false-go rates when cued items were in high proximity, $F(1,12)=14.55, p<.01$, $M S E=.004, \eta_{\mathrm{p}}^{2}=.55$, and when the distractor was a $\mathrm{T}$ rather than an $\mathrm{O}, F(1,12)=8.07, p=.02, M S E=.005, \eta_{\mathrm{p}}^{2}=$ .40 , but no significant interaction, $F<1, \eta_{\mathrm{p}}^{2}=.07$. In total, data gave no evidence of speed-accuracy trade-offs. Notably, evidence of parallel processing under lowproximity conditions was evident in data from all 13 subjects despite false-go rates ranging from a low of $7 \%$ to a high of $28 \%$, suggesting that the relatively high mean error rates for no-go trials did not bias the RT analyses.

\section{Discussion}

The data of Experiment 2 provide evidence for parallel processing of multiple items under low spatial interference and serial processing under high interference. In conjunction 
with the findings of Experiment 1, these results suggest that spatial interference between attended items can engender serial selection but may do so only at high levels.

\section{General discussion}

Previous research found highly inefficient divided attention under spatial interference but did not specify whether architecture remained parallel or became serial. To resolve this question, the present experiments manipulated the spatial proximity between attended items to produce conditions of low and high spatial interference and then employed the methods of SFT (Townsend \& Nozawa, 1995) to test processing architecture under both conditions. Analyses at the level of both mean RTs and RT distributions in Experiment 1 confirmed that parallel processing at the stage of feature integration and object resolution persisted when the attended items were adjacent to one another within the same quadrant of the visual field. Experiment 2, however, in which the density of objects within the stimulus displays was increased, found evidence of parallel processing for items widely separated in the visual field and serial processing for items in high proximity. Together, these effects indicate that parallel processing of multiple attended stimuli is possible under conditions of low or moderate spatial interference but gives way to serial processing under strong interference. Results comport well with models of visual selective attention as a competition for the control of neural responses, wherein the dominant object suppresses competing items within a set of shared RFs in a winner-take-all manner (Desimone \& Duncan, 1995; Tsotsos et al., 1995).

A variety of considerations confirm that serial processing was the result of attentional interactions modulated by the distance between cued items, ruling out multiple alternative possibilities. First, serial selection was not simply the consequence of placing two attended items within the same visual hemifield. This possibility is precluded by the findings of Experiment 1, which also presented attended items within the same quadrant of the visual field in high-proximity conditions but, nonetheless, found parallel processing. Second, serial processing was not due to the general nature or difficulty of the discrimination being made; the shape discrimination demanded of subjects was the same under the conditions that precipitated serial selection and those that allowed parallel selection. Thus, although the discrimination between rotated $\mathrm{T}$ and rotated $\mathrm{L}$ shapes is generally inefficient (Huang \& Pashler, 2005; Wolfe, 1998), the present results suggest that it may require serial processing only under conditions of high interference between attended items. This does not imply that a more difficult discrimination might not demand serial selection under conditions of low spatial interference (e.g., Sung, 2008; Woodman \& Luck, 1999, 2003), but it confirms that the nature of the discrimination used in this study did not by itself engender serial processing.

Finally, serial selection did not result from low-level crowding (Felisberti et al., 2005; Whitney \& Levi, 2011; Yeshurun \& Rashal, 2010) or from limits on the spatial resolution with which attention can select an individual item (Intriligator \& Cavanagh, 2001). This conclusion follows from the fact that the general arrangement of stimulus characters-fillers and cued items-within the displays of Experiment 2 was matched across high- and low-proximity conditions. Given that the spacing of stimulus characters within the displays was constant, processing constraints imposed by stimulus spacing in and of itself should have been similar regardless of whether cued items were adjacent or widely separated. Therefore, although stimulus density amplified the strength of interference between cued items, the interference itself was driven by the allocation of spatial attention. This result parallels earlier findings that have ruled out sensory interference as a cause of difficulty in dividing attention between items in high proximity to one another (Bahcall \& Kowler, 1999; McCarley et al., 2004; Mounts \& Gavett, 2004) and accords with findings that observers may have difficulty dividing attention over multiple objects within a small region of space even when they have little difficulty isolating a single object (Bahcall \& Kowler, 1999; Franconeri et al., 2007; McCarley et al., 2004).

In sum, the present data demonstrate that strong reciprocal interference between stimuli can prompt serial selection in a divided attention task, even if parallel selection is possible under weaker interference. Results do not indicate whether a transition to serial processing by itself fully explains the psychophysical costs of spatial interference in divided attention. McCarley et al. (2007) found that redundancy gains in a shape discrimination task abated gradually as target stimuli were moved closer together in the visual field, and they took their data as evidence that increasing spatial interference induced less efficient parallel processing. This could be accomplished either by allocating neurons discretely to different objects, as in Bundesen, Haberkost, and Kyllingsbæk (2005) neural theory of visual attention, or by allowing individual neurons to process multiple objects simultaneously but with different weights, as in Ghose and Maunsell's (2008) spatial summation model.

The present findings allow instead, however, that spatial interference might simply shift the balance of parallel and serial trials within a mixture distribution. In Experiment 1, although markers of parallel processing in the group mean MIC and SIC remained significant when attended items were in high proximity, they were nonetheless attenuated. In the high-proximity condition of Experiment 1 and the low-proximity condition of Experiment 2, furthermore, group mean SICs not only showed the pronounced negative deflection predicted by a parallel processing model, but also 
evinced modest positive deflections as well. Although far smaller than that predicted by a serial model, these positive bumps still appeared to violate the parallel model's prediction of SIC values consistently less than or equal to 0 . Together, these various findings suggest divided attentional processing that was parallel on a large majority of trials but may have lapsed on occasional trials into serial selection. As such, the effect of increased interference may have been not to slow the rate of parallel processing, but to increase the probability with which processing became serial. The psychophysical costs of increasing proximity between attended objects might therefore reflect a probabilistic transition from predominantly parallel to predominantly serial processing. Analyses designed to identify mixtures of discrete basis distributions (Yantis, Meyer, \& Smith, 1991) offer an avenue for exploring this possibility in future work.

A model positing a probabilistic transition from parallel to serial processing, finally, may explain why decreasing spatial separation between attended objects sometimes degrades perceptual quality and sometimes does not. Such an account predicts two circumstances under which spatial interference between attended stimuli should be absent. First, decreasing separation should have little influence if parallel processing remains possible even when attended stimuli are in high proximity. This might generally be the case when judgments can be based on the low-resolution feedforward sweep of neural activation that follows stimulus onset (Di Lollo, Enns, \& Rensink, 2000), without the need to carefully resolve or integrate the features of the attended objects, and in fact, past work has demonstrated that spatial interference between attended stimuli is weak or absent under these conditions (McCarley et al., 2012; SteelmanAllen, McCarley, \& Mounts, 2009). McCarley and Mounts (2007), for example, found no spatial attentional interference in feature detection judgments (Treisman \& Gelade, 1980), known to be possible on the basis of feedforward processing (Bouvier \& Treisman, 2010). Control experiments in McCarley and Mounts's study confirmed that feature detection indeed remained parallel as the distance between targets decreased.

Second, as has been suggested by Van Rullen et al. (2005), decreasing separation between attended items should have little effect on performance if serial processing is necessary even when stimuli are distant from one another. This prediction finds support in VanRullen et al.'s demonstration that performance on a pair of difficult same-different discriminations was unaffected by the separation between target stimuli. However, further experimentation will be necessary to determine whether processing in these tasks was truly serial.

Author Note Yusuke Yamani and Arthur Kramer, Beckman Institute, University of Illinois at Urbana-Champaign. Jason S. McCarley,
Flinders University, South Australia. Jeffrey R. W. Mounts, the State University of New York at Geneseo. Thanks to Jeremy Wolfe, Alec Scharff, and an anonymous reviewer for helpful comments on an earlier version of the manuscript. Correspondence concerning this paper should be addressed to Yusuke Yamani, Beckman Institute, University of Illinois, 405 North Mathews, Urbana, IL 61801. Email: yamani1@illinois.edu.

\section{References}

Awh, E., \& Pashler, H. (2000). Evidence for split attention foci. Journal of Experimental Psychology. Human Perception and Performance, 26, 834-846.

Bahcall, D. O., \& Kowler, E. (1999). Attentional interference at small spatial separations. Vision Research, 39, 71-86.

Banich, M. T. (1998). The missing link: The role of interhemispheric interaction in attentional processing. Brain and Cognition, 36, $128-157$.

Bouvier, S., \& Treisman, A. (2010). Visual feature binding requires reentry. Psychological Science, 21, 200-204.

Bricolo, E., Gianesini, T., Fanini, A., Bundesen, C., \& Chelazzi, L. (2002). Serial attention mechanisms in visual search: A direct behavioral demonstration. Journal of Cognitive Neuroscience, 14, 980-993.

Broadbent, D. E. (1958). Perception and communication. London: Pergamon Press.

Bundesen, C. (1990). A theory of visual attention. Psychological Review, 97, 523-547.

Bundesen, C., Habekost, T., \& Kyllingsbæk, S. (2005). A neural theory of visual attention: Bridging cognition and neurophysiology. Psychological Review, 112, 291-328.

Bundesen, C., Kyllingsbæk, S., \& Larsen, A. (2003). Independent encoding of colors and shapes from two stimuli. Psychonomic Bulletin \& Review, 10, 474-479.

Caputo, G., \& Guerra, S. (1998). Attentional selection by distractor suppression. Vision Research, 5, 669-689.

Cohen, A., \& Ivry, R. (1991). Density effects in conjunction search: Evidence for a coarse location mechanism of feature integration. Journal of Experimental Psychology. Human Perception and Performance, 17, 891-901.

Colonius, H., \& Volberg, D. (1994). Distribution inequalities for parallel models with unlimited capacity. Journal of Mathematical Psychology, 38, 35-58.

Cousineau, D. (2005). Confidence intervals in within-subject designs: A simpler solution to Loftus and Masson's method. Tutorials in Quantitative Methods for Psychology, 1, 42-45.

Desimone, R. (1998). Visual attention mediated by biased competition in extrastriate visual cortex. Philosophical Transactions of the Royal Society B Biological Science, 353, 1245-1255.

Desimone, R., \& Duncan, J. (1995). Neural mechanisms of selective visual attention. Annual Review of Neuroscience, 18, 193-222.

Desimone, R., \& Gross, C. G. (1979). Visual areas in the temporal cortex of the macaque. Brain Research, 178, 363-380.

Di Lollo, V., Enns, J. T., \& Rensink, R. A. (2000). Competition for consciousness among visual events: The psychophysics of reentrant visual processes. Journal of Experimental Psychology. General, 129, 481-507.

Dosher, B. A., Han, S., \& Lu, Z.-L. (2004). Parallel processing in visual search asymmetry. Journal of Experimental Psychology. Human Perception and Performance, 30, 3-27.

Egeth, H., \& Dagenbach, D. (1991). Parallel versus serial processing in visual search: Further evidence from subadditive effects of visual quality. Journal of Experimental Psychology. Human Perception and Performance, 17, 551-660. 
Eriksen, C. W., \& Hoffman, J. E. (1973). The extent of processing of noise elements during selective encoding from visual displays. Perception \& Psychophysics, 14, 155-160.

Eriksen, C. W., \& St. James, J. D. (1986). Visual attention within and around the field of focal attention: A zoom lens model. Perception \& Psychophysics, 40, 225-240.

Felleman, D. J., \& Van Essen, D. C. (1987). Receptive field properties of neurons in area V3 of macaque monkeyextrastriate cortex. Journal of Neurophysiology, 57, 889-920.

Felisberti, F. M., Solomon, J. A., \& Morgan, M. J. (2005). The role of target salience in crowding. Perception, 34, 823-833.

Fifić, M., Nosofsky, R. M., \& Townsend, J. T. (2008a). Informationprocessing architectures in multidimensional classification: A validation test of the systems factorial technology. Journal of Experimental Psychology. Human Perception and Performance, 34, 356-375.

Fifić, M., \& Townsend, J. T. (2010). Information-processing alternatives to holistic perception: Identifying the mechanisms of secondary-level holism within a categorization paradigm. Journal of Experimental Psychology: Learning, Memory, and Cognition, 36, 1290-1313.

Fifić, M., Townsend, J. T., \& Eidels, A. (2008b). Studying visual search using systems factorial methodology with targetdistractor similarity as the factor. Perception \& Psychophysics, 70, 583-603.

Franconeri, S. L., Alvarez, G. A., \& Enns, J. T. (2007). How many locations can be selected at once? Journal of Experimental Psychology. Human Perception and Performance, 33, 10031012.

Fuchs, S., Andersen, S. K., Gruber, T., \& Muller, M. M. (2008). Attentional bias of competitive interactions in neuronal networks of early visual processing in the human brain. NeuroImage, 41, 1086-1101.

Gatass, R., Sousa, A. P. B., \& Gross, C. G. (1988). Visuotopic organization and extent of V3 and V4 of the macaque. Journal of Neuroscience, 8, 1831-1845.

Ghose, G. M., \& Maunsell, J. H. R. (2008). Spatial summation can explain the attentional modulation of neuronal responses to multiple stimuli in area V4. Journal of Neuroscience, 28, 5115-5126.

Hahn, S., \& Kramer, A. F. (1998). Further evidence for the division of attention among non-contiguous locations. Visual Cognition, 5, 217-256.

Handy, T. C., \& Khoe, W. (2005). Attention and sensory gain control: A peripheral visual process? Journal of Cognitive Neuroscience, 17, 1936-1949.

Hilimire, M. R., Mounts, J. R. W., Parks, N. A., \& Corballis, P. M. (2009). Competitive interaction degrades target selection: An ERP study. Psychophysiology, 46, 1080-1089.

Hogendoorn, H., Carlson, T. A., Van Rullen, R., \& Verstraten, F. A. J. (2010). Timing divided attention. Attention, Perception, \& Psychophysics, 72, 2059-2068.

Houpt, J. W., \& Townsend, J. T. (2010). The statistical properties of the survivor interaction contrast. Journal of Mathematical Psychology, 54, 446-453.

Huang, K., \& Pashler, H. (2005). Attention capacity and task difficulty in visual search. Cognition, 94, 101-111.

Hubel, D. H., \& Wiesel, T. N. (1968). Receptive fields and functional architecture of monkey striate cortex. The Journal of Physiology, $195,215-243$

Intriligator, J., \& Cavanagh, P. (2001). The spatial resolution of visual attention. Cognitive Psychology, 43, 171-216.

Kastner, S., De Weerd, P., Desimone, R., \& Ungerleider, L. G. (1998). Mechanisms of directed attention in the human extrastriate cortex as revealed by functional MRI. Science, 282, 108-111.

Kastner, S., De Weerd, P., Pinsk, M. A., Elizondo, M. I., Desimone, R., \& Ungerleider, L. G. (2001). Modulation of sensory suppression:
Implications for receptive field sizes in the human visual cortex. Journal of Neurophysiology, 85, 1398-1411.

Kastner, S., \& Ungerleider, L. G. (2000). Mechanisms of visual attention in the human cortex. Annual Review of Neuroscience, 23, 315-341.

Kramer, A. F., \& Hahn, S. (1995). Splitting the beam: Distribution of attention over noncontiguous regions of the visual field. Psychological Science, 6, 381-386.

Kyllingsbæk, S., \& Bundesen, C. (2007). Parallel processing in a multifeature whole-report paradigm. Journal of Experimental Psychology. Human Perception and Performance, 33, 64-82.

Luck, S. J., \& Beach, N. J. (1998). Visual attention and the binding problem: A neurophysiological perspective. In R. D. Wright (Ed.), Visual attention (pp. 455-478). Oxford, UK: Oxford University Press.

Luck, S. J., Girelli, M., McDermott, M. T., \& Ford, M. A. (1997). Bridging the gap between monkey neurophysiology and human perception: An ambiguity resolution theory of visual selective attention. Cognitive Psychology, 33, 64-87.

McCarley, J. S., \& Mounts, J. R. W. (2007). Localized attentional interference affects object individuation, not feature detection. Perception, 36, 17-32.

McCarley, J. S., Mounts, J. R. W., \& Kramer, A. F. (2004). Age-related differences in localized attentional interference. Psychology and Aging, 19, 203-210.

McCarley, J. S., Mounts, J. R. W., \& Kramer, A. F. (2007). Spatiallymediated capacity limits in attentive visual perception. Acta Psychologica, 126, 98-119.

McCarley, J. S., Yamani, Y., Mounts, J. R. W., \& Kramer, A. F. (2012). Age, clutter, and competitive selection. Psychology and Aging. doi:10.1037/a0026705. Online publication January 9.

McElree, B., \& Carrasco, M. (1999). The temporal dynamics of visual search: Evidence for parallel processing in feature and conjunction searches. Journal of Experimental Psychology: Human Perception and Performance, 25, 1517-1539.

Miller, J. O. (1982). Divided attention: Evidence for coactivation with redundant signals. Cognitive Psychology, 14, 247-279.

Miller, J., \& Bonnel, A.-M. (1994). Switching or sharing in dual-task linelength discrimination? Perception \& Psychophysics, 56, 431-446.

Moran, J., \& Desimone, R. (1985). Selective attention gates visual processing in the extrastriate cortex. Science, 229, 782-784.

Mordkoff, J. T., \& Yantis, S. (1991). An interactive race model of divided attention. Journal of Experimental Psychology. Human Perception and Performance, 17, 520-538.

Mordkoff, J. T., Yantis, S., \& Egeth, H. E. (1990). Detecting conjunctions of color and form in parallel. Journal of Experimental Psychology. Human Perception and Performance, 48, 157-168.

Morey, R. D. (2008). Confidence intervals from normalized data: A correction to Cousineau (2005). Tutorials in Quantitative Methods for Psychology, 4, 61-64.

Mounts, J. R. W. (2000a). Attentional capture by abrupt onsets and feature singletons produces inhibitory surrounds. Perception \& Psychophysics, 62, 1485-1493.

Mounts, J. R. W. (2000b). Evidence for suppressive mechanisms in attentional selection: Feature singletons produce inhibitory surrounds. Perception \& Psychophysics, 62, 969-983.

Mounts, J. R. W., \& Gavett, B. E. (2004). The role of salience in localized attentional interference. Vision Research, 3, 1575-1588.

Nozawa, G., Reuter-Lorenz, P. A., \& Hughes, H. C. (1994). Parallel and serial processes in the human oculomotor system: Bimodal integration and express saccades. Biological Cybernetics, 72, 19-34.

Pashler, H. E. (1987). Detecting conjunctions of color and form: Reassessing the serial search hypothesis. Perception \& Psychophysics, 41, 191-201.

Posner, M. I., Davidson, B. J., \& Snyder, C. R. R. (1980). Attention and the detection of signals. Journal of Experimental Psychology. General, 109, 160-174. 
Reddy, L., \& VanRullen, R. (2007). Spacing affects some but not all visual searches: Implications for theories of attention and crowding. Journal of Vision, 7, 1-17.

Reynolds, J. H., Chelazzi, L., \& Desimone, R. (1999). Competitive mechanisms subserve attention in macaque areas V2 and V4. Journal of Neuroscience, 19, 1736-1753.

Reynolds, J. H., \& Desimone, R. (1999). The role of neural mechanisms of attention in solving the binding problem. Neuron, 24, 19-29.

Roberts, M., Delicato, L. S., Herrero, J., Gieselmann, M. A., \& Thiele, A. (2007). Attention alters spatial integration in macaque V1 in an eccentricity-dependent manner. Nature Neuroscience, 10, 14831491.

Schweickert, R. (1978). A critical path generalization of the additive factor method: Analysis of a Stroop task. Journal of Mathematical Psychology, 18, 105-139.

Schweickert, R., \& Townsend, J. T. (1989). A trichotomy: Interactions of factors prolonging sequential and concurrent mental processes in stochastic discrete mental (PERT) networks. Journal of Mathematical Psychology, 33, 328-347.

Sereno, A. B., \& Kosslyn, S. M. (1991). Discrimination within and between hemifields: A new constraint on theories of attention. Neuropsychologia, 29, 659-675.

Smith, A. T., Singh, K. D., Williams, A. L., \& Greenlee, M. W. (2001). Estimating receptive field size from fMRI data in human striate and extrastriate visual cortex. Cerebral Cortex, 11, 1182-1190.

Sperling, G. (1960). The information available in brief visual presentations. Psychological Monographs: General and Applied, 74, 129.

Steelman-Allen, K. S., McCarley, J. S., \& Mounts, J. R. W. (2009). Localized attentional interference reflects competition for reentrant processing. Psychonomic Bulletin \& Review, 16, 110-115.

Sternberg, S. (1969). Memory scanning: Mental processes revealed by reaction-time experiments. American Scientist, 4, 421-457.

Sung, K. (2008). Serial and parallel attentive visual searches: Evidence from cumulative distribution functions of response times. Journal of Experimental Psychology. Human Perception and Performance, 34, 1372-1388.

Townsend, J. T. (1972). Some results concerning the identifiability of parallel and serial processes. British Journal of Mathematical and Statistical Psychology, 25, 168-199.

Townsend, J. T. (1990). Serial vs. parallel processing: Sometimes they look like tweedledum and tweedledee but they can (and should be) distinguished. Psychological Sciences, 1, 46-54.

Townsend, J. T., \& Ashby, F. G. (1983). Stochastic modeling of elementary psychological processes. Cambridge, England: Cambridge University Press.

Townsend, J. T., \& Eidels, A. (2011). Workload capacity spaces: A unified methodology for response time measures of efficiency as workload is varied. Psychonomic Bulletin \& Review, 18, 659-681.

Townsend, J. T., \& Fifić, M. (2004). Parallel versus serial processing and individual difference in high-speed search in human memory. Perception \& Psychophysics, 66, 953-962.

Townsend, J. T., \& Nozawa, G. (1995). On the spatio-temporal properties of elementary perception: An investigation of parallel, serial, and coactive theories. Journal of Mathematical Psychology, 39, 321-359.

Townsend, J. T., \& Wenger, M. J. (2004). The serial-parallel dilemma: A case study in a linkage of theory and method. Psychonomic Bulletin \& Review, 11, 391-418.

Treisman, A. (1996). The binding problem. Current Opinion in Neurobiology, 6, 171-178.

Treisman, A. M., \& Gelade, G. (1980). A feature-integration theory of attention. Cognitive Psychology, 12, 97-136.

Treisman, A. M., \& Schmidt, H. (1982). Illusory conjunctions in the perception of objects. Cognitive Psychology, 14, 107-141.

Tsotsos, J. K., Culhane, S. M., Kei Wai, W. Y., Lai, Y., Davis, N., \& Nuflo, F. (1995). Modeling visual attention via selective tuning. Artificial Intelligence, 78, 507-545.

Tsotsos, J. K., Rodríguez-Sánchez, A. J., Rothenstein, A. L., \& Simine, E. (2008). The different stages of visual recognition need different attentional binding strategies. Brain Research, 1225, 119-132.

van der Heijden, A. H. C. (1975). Some evidence for a limited capacity parallel self-terminating process in simple visual search tasks. Acta Psychologica, 39, 21-41.

van der Heijden, A. H. C., La Heij, W., \& Boer, J. P. A. (1983). Parallel processing of redundant targets in simple visual search tasks. Psychological Research, 45, 235-254.

VanRullen, R., Reddy, L., \& Fei-fei, L. (2005). Binding is a local problem for natural objects and scenes. Vision Research, 45, 3133-3144.

Whitney, D., \& Levi, D. M. (2011). Visual crowding: a fundamental limit on conscious perception and object recognition. Trends in Cognitive Sciences, 15, 160-168.

Wolfe, J. M. (1994). Guided search 2.0: A revised model of visual search. Psychonomic Bulletin \& Review, 1, 202-238.

Wolfe, J. M. (1998). Visual search. In H. Pashler (Ed.), Attention (pp. 13-73). East Sussex: Psychology Press.

Wolfe, J. M. (2003). Moving towards solutions to some enduring controversies in visual search. Trends in Cognitive Science, 7, 70-76.

Wolfe, J. M., \& Bennett, S. C. (1997). Preattentive object files: Shapeless bundles of basic features. Vision Research, 37, 25-43.

Wolfe, J. M., Cave, K. R., \& Franzel, S. L. (1989). Guided search: An alternative to feature integration model for visual search. Journal of Experimental Psychology. Human Perception and Performance, 15, 419-433.

Womelsdorf, T., Anton-Erxleben, K., \& Treue, S. (2008). Receptive field shift and shrinkage in macaque middle temporal area through attentional gain modulation. Journal of Neuroscience, 28, 8934-8944.

Woodman, G. F., \& Luck, S. J. (1999). Electrophysiological measurement of rapid shifts of attention during visual search. Nature, 400, $867-869$.

Woodman, G. F., \& Luck, S. J. (2003). Serial deployment of attention during visual search. Journal of Experimental Psychology. Human Perception and Performance, 29, 121-138.

Yantis, S., Meyer, D. E., \& Smith, J. K. (1991). Analysis of multinomial mixture distributions: New tests for stochastic models of cognition and action. Psychological Bulletin, 110, 350-374.

Yeshurun, Y., \& Rashal, E. (2010). Precueing attention to the target location diminishes crowding and reduces the critical distance. Journal of Vision, 10:16, 1-12. 